\title{
Ocular pulse amplitude in diabetes mellitus
}

\author{
Karl-Georg Schmidt, Andrea von Rückmann, Bettina Kemkes-Matthes, \\ Hans-Peter Hammes
}

\begin{abstract}
Background-The influence of diabetes mellitus on ocular pulse amplitude (OPA), an indirect measure of choroidal perfusion, is unclear.

Methods-OPA, using the Langham ocular blood flow (OBF) system, applanation intraocular pressure (IOP), systemic blood pressure (BP), heart rate, and haemoglobin ( $\mathrm{Hb}) A_{1 \mathrm{c}}$ were measured in patients with insulin dependent diabetes mellitus (IDDM) with no (DR-0, $\mathbf{n}=22)$ non-proliferative (DR-1, $n=24)$, and proliferative $(\mathrm{DR}-2, \mathrm{n}=18)$ diabetic retinopathy.

Results-Neither local (OPA, IOP) nor systemic perfusion parameters (BPs, HR) nor $\mathbf{H b A}_{1 \mathrm{c}}$ were significantly altered in DR-0, DR-1, or DR-2 IDDM patients. Conclusion-Choroidal circulation remains unaffected as diabetic retinopathy advances.

(Br F Ophthalmol 2000;84:1282-1284)
\end{abstract}

Diabetic retinopathy (DR) is the major cause of blindness in adults aged $25-74$ years. ${ }^{1}$ With increasing duration of this disease, the inner retina is progressively affected by microvascular occlusions leading to reduced oxygen supply and eventually retinal neovascularisation. $^{2}$

Although the underlying cause of DR is related to chronic hyperglycaemia, the exact sequence of events and the relative contributions of abnormalities within the vessel ${ }^{3-5}$ and the vessel wall are undetermined. ${ }^{67}$

Changes in retinal perfusion, its regulation, and the factors that mediate them have been studied in diabetes mellitus (DM) by many investigators. ${ }^{8-12}$

A review of the literature also suggests a pathogenetic role for the choroid in the initiation and propagation of DR. Using scanning electron microscopy in necropsy eyes from patients with long standing insulin dependent DM (IDDM), Fryczkowsky et al ${ }^{13}$ noted increased tortuosity, focal vascular dilatations and narrowings, vascular loops and microaneurysm formation, dropout of choriocapillaries, and sinus-like structure formation between choroidal lobules in the equatorial area. They concluded that changes in the choroid, especially in the choriocapillaris, may be a contributing factor in DR, resulting in decreased oxygenation of the outer layers of the retina.

High resolution histological analysis of the human choroidal vasculature revealed capillary dropout, beaded capillaries, and neovascularisation, ${ }^{14}$ fluorescein angiography showed delayed choroidal perfusion, and electroretinograms with abnormal oscillatory potentials in the same DM patients. ${ }^{15}$

The choroid supplies $80 \%$ of total retinal oxygen $^{16}$ and glucose, ${ }^{17}$ and all of the nutrients to the macula and optic disc region, ${ }^{18}$ and maintains a constant thermal environment for the retina. ${ }^{16}{ }^{17}$

Reduced blood flow can result in tissue hypoxia, leading in extreme situations to cell/tissue death-for example, in myocardial or cerebral tissue infarctions. Results from clinical studies showed reduced choroidal perfusion in $\mathrm{DR},{ }^{19}$ retinitis pigmentosa,${ }^{20}$ and normal tension glaucoma. ${ }^{21-23}$ associated with functional (visual field defects) and morphological (nerve fibre layer loss) damage. ${ }^{22}{ }^{23}$

Increased choroidal perfusion as noted in ocular hypertensive patients ${ }^{22}{ }^{24}$ and following application of nifedipine ${ }^{2526}$ and dorzolamide $^{2728}$ may be interpreted as a protective mechanism.

This study was designed to evaluate ocular pulse amplitude (OPA), in IDDM patients with different stages of DR.

OPA is an indirect measure of choroidal perfusion. A bolus of blood entering the eye corresponding to the cardiac pulse represents a change of intraocular pressure (IOP) as a function of time reflecting the pulsatile component (approximately $70 \%)^{29}$ of intraocular blood flow, ${ }^{30} 85 \%$ of which is choroidal. ${ }^{32}$

\section{Materials and methods}

Sixty four patients with type 1 insulin dependent diabetes mellitus (IDDM) taking intensified insulin therapy were investigated. Patients with systemic hypertension, hypercholesterolaemia, neurological deficits, typical migraine headache, and ocular or systemic disease, other than the category selected for, were excluded from the study. The IDDM patients selected had a history of IOP $<21 \mathrm{~mm} \mathrm{Hg}$, typical fundus appearance (DR-0: normal fundus, DR-1: background diabetic retinopathy characterised by microaneurysms, haemorrhages, exudates, oedema, nerve fibre layer infarcts, venous beading, and/or intraretinal microvascular abnormalities; DR-2: proliferative diabetic retinopathy characterised by an area of epipapillary neovascularisation larger than a quarter of disc diameter and/or areas of epiretinal neovascularisation larger than a diameter of half a disc). None of the patients or controls had received ocular surgery or laser treatment of any kind and were taking no ocular therapy.

Patients with DR-0 ( $\mathrm{n}=22$, male: 12 , age: 23.3 (SD 2.2) years, duration of diabetes: 5.5 (1.8) years, $\mathrm{HBA}_{1 \mathrm{c}}$ : $6.1(0.5)$ ); DR-1 $(\mathrm{n}=24$, male: 11, age: 28.4 (2.6) years, duration of 
Table 1 Comparison of perfusion parameters (mean (SD)) of patients with insulin dependent diabetes mellitus (IDDM) with different stages of diabetic retinopathy, no (DR-0, $n=22)$ non-proliferative $(D R-1, n=24)$, and proliferative (DR-2, $n=18$ ) diabetic retinopathy compared with matched subgroups (MCTL) from a pool of healthy controls $(C T L, n=72)$

\begin{tabular}{|c|c|c|c|c|c|c|c|c|c|c|}
\hline \multirow[b]{2}{*}{ Control (CTL) } & \multicolumn{2}{|c|}{$O P A(m m ~ H g)$} & \multicolumn{2}{|c|}{$I O P(m m ~ H g)$} & \multicolumn{2}{|c|}{$\begin{array}{l}\text { Blood pressure (systolic, } \\
m m \mathrm{Hg} \text { ) }\end{array}$} & \multicolumn{2}{|c|}{$\begin{array}{l}\text { Blood pressure } \\
\text { (diastolic, } \mathrm{mm} \mathrm{Hg} \text { ) }\end{array}$} & \multicolumn{2}{|c|}{$\begin{array}{l}\text { Heart rate } \\
\text { (beats } / \text { min) }\end{array}$} \\
\hline & 2.2 & $(0.5)$ & 15.1 & (1.5) & 125.1 & $(14.2)$ & 78.2 & $(10.7)$ & 77.0 & $(15.0)$ \\
\hline DR-0 & 2.4 & $(0.7)$ & 15.8 & (4.3) & 129.4 & (17.6) & 78.6 & (10.9) & 76.2 & $(20.5)$ \\
\hline Matched CV & 2.2 & $(0.7)$ & 14.9 & (2.4) & 123.4 & $(24.9)$ & 77.4 & $(8.8)$ & 77.7 & (16.8) \\
\hline DR-1 & 2.2 & $(0.8)$ & 16.4 & (5.2) & 125.0 & $(23.8)$ & 80.1 & $(10.3)$ & 79.9 & $(9.5)$ \\
\hline Matched CTL & 2.2 & $(0.8)$ & 15.0 & (2.6) & 127.1 & $(20.4)$ & 76.7 & $(10.2)$ & 76.3 & (12.3) \\
\hline DR-2 & 2.1 & $(0.7)$ & 16.2 & (5.4) & 119.7 & (22.3) & 75.7 & $(13.9)$ & 77.1 & $(19.2)$ \\
\hline Matched CTL & 2.3 & $(0.5)$ & 15.2 & (2.4) & 124.5 & $(24.2)$ & 78.9 & $(17.9)$ & 76.6 & (15.1) \\
\hline
\end{tabular}

There were no significant changes in any of the parameters using Student's unpaired two tailed $t$ test.

diabetes: 11.3 (2.6) years, $\left.\mathrm{HBA}_{1 \mathrm{c}}: 5.8(0.4)\right)$; and DR-2 ( $\mathrm{n}=18$, male: 9, age: 33.1 (2.5) years, duration of diabetes: 16.1 (3.2) years, $\mathrm{HBA}_{1 \mathrm{c}}$ : 6.3 (0.7)) were compared with respective matched control subgroups (MCTL) selected from a pool of 72 healthy volunteers with no known ocular or systemic disease, who showed no visual field defects and/or disc alterations and had IOPs $<21 \mathrm{~mm} \mathrm{Hg}$ matched for age (SD 3 years), sex, IOP (2) $\mathrm{mm} \mathrm{Hg}$ ), and refraction (1.5 dioptres spherical equivalent).

The study has been approved by the institutional review board and informed consent was obtained from each patient/volunteer following complete explanation of the procedure.

The ocular blood flow (OBF) system (OBF Labs Ltd, Wiltshire) has been described in detail elsewhere. ${ }^{31}$

In addition to pneumotonometric values, IOP was measured by Goldmann applanation tonometry. Brachial artery pressures were measured non-invasively (Riva-Rocci) using a blood pressure cuff and a stethoscope after 5 minutes resting. Heart rate (HR) was measured manually using a stopwatch. Applanation IOP, blood pressure (BP), and HR were taken before OPA measurements. All measurements were performed in a seated position, respective measurements were taken by the same examiner.

STATISTICS

All data represent arithmetic mean (SD); Student's unpaired two tailed $t$ test was used for statistical analysis. Measurements were per-

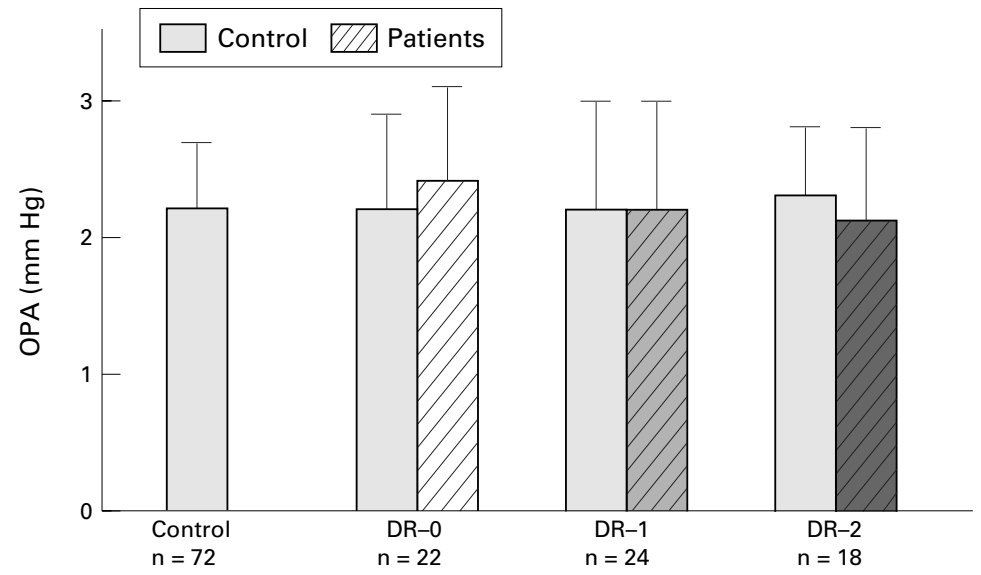

Figure 1 Ocular pulse amplitudes (OPA; mean (SD)) of patients with insulin dependent diabetes mellitus with different stages of diabetic retinopathy, no $(D R-0, n=22)$, non-proliferative (DR-1, $n=24)$, and proliferative (DR-2, $n=18$ ) diabetic retinopathy compared with matched subgroups from a pool of healthy controls $(n=72)$. There were no significant changes in any of the parameters shown in this diagram using Student's unpaired two tailed $t$ test. formed on both eyes of each subject. The level of significance was $5 \%$. IDDM patient groups (DR-0, DR-1, DR-2) were compared with matched subgroups (MCTL) of healthy volunteers (CTL), and with each other.

\section{Results}

When compared with respective subgroups from a pool of healthy controls $(n=72)$, IOP, OPA (Fig 1), systolic and diastolic blood pressures, and heart rate (Table 1) were not significantly $(p>0.1)$ altered in any of the three IDDM groups investigated.

Also, when IDDM patient groups were compared with each other IOP, OPA (Fig 1), systolic and diastolic blood pressures, heart rate, and $\mathrm{HBA}_{1 \mathrm{c}}$ were not significantly $(\mathrm{p}>0.1)$ altered in any of the three IDDM groups (Table 1).

\section{Discussion}

OPA, a haemodynamic parameter reflecting overall choroidal perfusion is unchanged in IDDM patients independent of the degree of retinopathy which is in contrast with another study reporting a reduction of OPA with the severity of the retinopathy. ${ }^{19}$

The functional integrity of the choroid in DR even in advanced stages, as demonstrated by our data, is confirmed by clinical evidence that the function of the photoreceptors as measured by visual field examination is unaltered in DR. ${ }^{32}$

In parallel with the anatomy and the physiological function of both vascular systems, DR is confined to the inner parts of the retina, ${ }^{33}$ the outer plexiform layer, the watershed zone between retinal and choroidal vascular system, being the most outer zone affected, ${ }^{33}$ whereas the outer retina beginning at the outer plexiform layer, supplied by the choroid, ${ }^{18}$ remains mostly unaltered. ${ }^{33}$

Despite similar metabolic changes affecting both retinal and choroidal vascular beds, ${ }^{34}$ one interesting finding is that pericyte dropout, a hallmark of early diabetic retinopathy does not occur in choroidal capillaries. ${ }^{35}$ The primary surplus of choroidal vessels and blood flow, responsible for the nutrition and waste removal of the crucial outer retinal parts, may in part explain the relative resistance to degenerative influences from disease such as diabetic retinopathy.

\footnotetext{
Proprietary interest: none.

1 Moss SE, Klein R, Klein BE. Ten-year incidence of visual loss in a diabetic population. Ophthalmology 1994;101:1061-70.
} 
2 Jing ZY, Towler HMA, Luthert P, et al. Pathophysiology of diabetic retinopathy. In: LeRoith D, Taylor SI, Olefsky JM, eds. Diabetes mellitus.
Raven, 1996:719-37.

3 Ernst E, Matrai A. Altered red and white blood cell rheology in type II diabetes. Diabetes 1986;35:1412-5.

4 Wautier JL, Paton RC, Wautier MP, et al. Increased adhesion of erythrocytes to endothelial cells in diabetes mellitus and its relation to vascular complications. $N$ Engl f Med 1981;305:237-42.

5 Setiadi H, Wautier JL, Courillon-Mallet A, et al. Increased adhesion to fibronectin and Mo-1 expression in diabetic monocytes. F Immunol 1987;138:3230-4.

6 DCCT Research Group. The effect of intensive treatment of diabetes on the development and progression of long-term complications in insulin-dependent diabetes mellitus. N Engl f Med 1993;329:977-86.

7 Brownlee M. Lilly lecture 1993. Glycation and diabetic complications. Diabetes 1994;43:836-41.

8 Yoshida A, Feke GT, Moralles-Stoppello J, et al. Retinal blood flow alterations during the progression of diabetic blood flow alterations during the progression
retinopathy. Arch Ophthalmol 1983;101:225-7.

9 Grunwald JE, Riva CE, Sinclair SH, et al. Laser Doppler velocimetry study of retinal circulation in diabetes mellitus. Arch Ophthalmol 1986;104:991-6.

10 Patel V, Rassam S, Kohner E, et al. Retinal blood flow in diabetic retinopathy. BMF 1992;305:678-83.

11 Feke GT, Buzney SM, Ogasawara H, et al. Retinal circulatory abnormalities in type I diabetes. Invest Ophthalmol Vis Sci 1994;35:2968-75.

12 Bursell SE, Clermont AC, Brendan TK, et al. Retinal blood flow changes in patients with insulin-dependent diabetes mellitus and no diabetic retinopathy. Invest Ophthalmol Vis Sci 1996;37:886-97.

13 Fryczkowski AW, Hodes BL, Walker J. Diabetic choroidal vasculature scanning electron microscopy findings. Int Ophthalmol 1989;13:269-79.

14 McLeod DS, Lutty GA. High-resolution histologic analysis of the human choroidal vasculature. Invest Ophthalmol Vis of the human choroida

15 Caldwell RB, Fitzgerald ME. The choriocapillaris in spontaneously diabetic rats. Microvasc Res 1991;42:229spontan.
44.

16 Alm A, Bill A. The oxygen supply to the retina. II. Effects of high intraocular pressure and increased arterial carbon dioxide tension on uveal and retinal blood flow in cats. Acto Physiol Scand 1972;84:306-19.

17 Törnquist P, Alm A. Retinal and choroidal contribution to retinal metabolism in vivo. A study in pigs. Acta Physio Scand 1979;106:351-7.

18 Alm A. Ocular circulation. In: Hart WM, ed. Adler's physiology of the eye. St Louis: CV Mosby, 1992:198-227.

19 Langham ME, Grebe R, Hopkins M, et al. Choroidal blood flow in diabetic retinopathy. Exp Eye Res 1991;52:167-73.
20 Langham ME, Kramer T. Decreased choroidal blood flow associated with retinitis pigmentosa. Eye 1990;4:374-81.

21 Schmidt KG, v Rückmann A, Mittag TW, et al. Reduced ocular pulse amplitude in low tension glaucoma is independent of vasospasm. Eye 1997;11:485-8.

22 Schmidt KG, v Rückmann A, Mittag TW. Okuläre Pulsamplitude bei okulärer Hypertension und verschiedenen Glaukomformen. Ophthalmologica 1998;212:5-10.

23 Mittag TW, Serle J, Schumer R, et al. Studies of the ocular pulse in primates. Surv Ophthalmol 1994;38(Suppl):18390 .

24 Trew DR, Smith SE. Postural studies in pulsatile blood flow: I. Ocular hypertension and normotension. $\mathrm{Br} \mathcal{F} \mathrm{Oph}$ thalmol 1991;75:66-70.

25 Schmidt KG, Mittag TW, Pavlovic S, et al. Influence of physical exercise and nifedipine on ocular pulse amplitude. Graefes Arch Clin Exp Ophthalmol 1996;234:527-32.

26 Schmidt KG, v Rückmann A, Geyer O, et al. Einflu $\beta$ des Nifedipins auf die okuläre Pulsamplitude bei Normaldruckglaukom. Klin Monatsbl Augenheilkd 1997;210: 355-9.

27 Schmidt KG, v Rückmann A, Pillunat LE. Dorzolamide increases ocular pulse amplitude in high tension primary open angle glaucoma. Br f Ophthalmol 1998;82:758-62.

28 Schmidt KG. Antiglaukomatosa und choroidale Perfusion bei primärem und experimentell induziertem Offenwinkelglaukom. In: Schmidt KG, Pillunat LE, eds. Fortbildung glaukom, bd 1, perfusion und pharmakologie. Stuttgart: Enke, 1999:39-50.

29 Williamson TH, Harris A. Ocular blood flow measurement. Br f Ophthalmol 1994;78:939-45.

30 Silver DM, Farrell RA. Validity of pulsatile ocular blood flow measurements. Surv Ophthalmol 1994;38(Suppl):7280 .

31 Schmidt KG. Basic principle of the OBF-System. In: Pillunat LE, Harris A, Anderson DR, Greve EL, eds. Current concepts on ocular blood flow in glaucoma. The Hague: Kugler, 1999:75-95.

32 Zetterstrom B. Results of photocoagulation in diabetic retinopathy after long-term follow-up. Acta Ophthalmol Copenh 1980;58:361-8.

33 Kanski JJ. Diabetic retinopathy. In: Kanski JJ, ed. Clinical ophthalmology. Stuttgart, New York: Thieme, 1996:330-63.

34 MacGregor LC, Rosecan LR, Laties AM, et al. Altered retinal metabolism in diabetes. I. Microanalysis of lipid, glucose, sorbitol, and myo-inositol in the choroid and in the individual layers of the rabbit retina. F Biol Chem 1986;261: 4046-51.

35 Tilton RG, LaRose LS, Kilo C, et al. Absence of degenerative changes in retinal and uveal capillary pericytes in diabetic rats. Invest Ophthalmol Vis Sci 1986;27:716-21. 